\title{
Traversing the Quality Chasm: Revisiting the Framework for Pharmacy Services Quality Improvement
}

Mel L. Nelson, PharmD, CPHQ; Carter Chapman, PharmD, CPHQ; and Patrick J. Campbell, PharmD, PhD

$\mathrm{P}$ ublished by JMCP in 2004, "Framework for Pharmacy Services Quality Improvement-A Bridge to Cross the Quality Chasm," is an article that seemingly could have been printed yesterday. ${ }^{1}$ Its delineation of the core components that characterize pharmacy practice across care settings is akin to recent articles describing the continued development of enhanced pharmacy service models. It is astonishing that this article was published over 15 years ago and still has such relevance today. ${ }^{2}$

The evolution of pharmacy practice, including the emergence of collaborative drug therapy management agreements, mobilized professional pharmacy associations to advocate collectively for pharmacy provider status legislation. ${ }^{3}$ By the time this framework was created, pharmacy practice had already progressed considerably, representing a profession inclusive of a comprehensive set of clinical, educational, and consultative services. ${ }^{4}$ Although practice has continued to evolve since then, the pharmacy service descriptions and associated framework from 2004 are fairly representative of and applicable to pharmacy services as they exist today.

The impetus for framework development occurred largely in response to the health care system's increased focus on quality, particularly with the release of 2 landmark reports by the Institute of Medicine that garnered tremendous public attention. The first report, To Err Is Human: Building a Safer Health System, underscored the intensity and gravity of medication errors and provided an agenda to reduce preventable errors by designing a system of safer care. ${ }^{5}$ The second report, Crossing the Quality Chasm: A New Health System for the 21st Century, described a broader set of health care performance expectations and made an urgent call to close those quality gaps. ${ }^{6}$ These seminal publications precipitated a quality-focused transformation of the U.S. health care system.

The continued relevancy of the 2004 article by Curtiss et al. can, in part, be attributed to their robust approach to developing the pharmacy services quality improvement framework. To

\section{J Manag Care Spec Pharm. 2020;26(7):817-19}

Copyright $\odot 2020$, Academy of Managed Care Pharmacy. All rights reserved. bridge the quality chasm, the authors leveraged insights from the pharmacy profession and those served by the profession (e.g., patients and providers) to inform the framework and ensure applicability across practice settings and relevancy to all stakeholders. The resulting framework delineated a number of processes across core focus areas that advance desired economic, clinical, and humanistic outcomes. ${ }^{1}$

\section{"Quality improvement in health care services in the United States will be made in incremental changes that rely on a structure-process-outcome model."1}

The health care environment has undergone a variety of changes since the 2004 article was initially published, and its continued relevance today underscores the forwardthinking nature of the work. Many of these changes have been incremental, and we are now in an era where quality is commonplace in the health care landscape. The 2004 article was published before the implementation of the Medicare Part D Prescription Drug Program in 2006, which solidified the pharmacist's role as a medication therapy expert. This historic event catapulted the federal government into position as one of the largest single payers of prescription drugs.

As such, the Centers for Medicare \& Medicaid Services (CMS) recognized that high-value pharmacy services would drive improved performance and quality of care. To meet the need for meaningful metrics to benchmark and optimize medication use, CMS created the Pharmacy Quality Alliance (PQA) in April 2006 as a public-private partnership. PQA was specifically established as a multistakeholder, consensus-based entity to develop metrics addressing appropriate prescribing, monitoring, and management of drug therapy, the assessment of which is one of the hallmarks of the framework. These metrics were initially used for health plan accountability within the Medicare Part D program to incentivize quality improvement activities in order to advance patient outcomes. Defining, developing, and implementing medication use quality measures became the focus of PQA, which eventually evolved into a free-standing nonprofit organization in 2008 that still focuses on optimizing medication use quality to this day. ${ }^{7}$ 
In response to the proliferation of quality payment programs and increased focus on quality, health care organizations have created many new positions to keep pace with the evolving quality landscape. The title of chief quality officer and chief patient officer were not commonplace in 2004, but today many organizations have dedicated teams focused on quality. CMS star ratings experts are now common in health plans and pharmacy benefit managers, and these experts are tasked with finding ways to improve the quality of care tied to quality bonus payments. Many of these quality-related positions are champions of continuous quality improvement (CQI), the Donabedian structure-process-outcome model, ${ }^{8}$ and the ideals set forth in the framework, including that of being patient-centered.

\section{Framework authors viewed it "as a roadmap that can guide change."1}

A number of key issues and opportunities enumerated in the framework's self-assessment tool remain major themes in health care and pharmacy today, emphasizing the continued utility of the tool. These common themes include collaborative practice agreements, interoperable access to health information across care settings, and patient centricity, among others.

Innovative value-based care models increasingly permeate all areas of our health care system, including partnerships among hospitals, case workers, and pharmacists to improve outcomes after hospitalization by ensuring smooth transitions among care settings.,10 Clinical pharmacy services are increasingly embedded in ambulatory care through patientcentered medical homes, federally qualified health centers, and chronic disease management clinics. Yet, although we are seeing continued growth, pharmacy still faces a number of the same challenges and barriers it did when the framework was created, including access to clinical data and recognition of pharmacists as health care providers.

The availability of data and how they are used in health care is very different today than 2004 , which was a time before the world was interconnected through social media and the advent of wearable technologies. Interoperability of health systems data has advanced remarkably in ways that were not even a forethought at that time. In 2004, pharmacist access to health information was primarily rooted in the dispensing system, limiting the ability to adequately assess drug therapy. Now, depending on the setting, pharmacists may have access to platforms that identify high-risk patients for targeted interventions. Additionally, health care apps have proliferated, allowing patients to more easily share their information. Yet, pharmacists (particularly those in the community and closest to patients) still face barriers to obtaining patient clinical data, such as diagnosis and relevant laboratory values that can aid in medication optimization and resultant outcomes. Achieving secure, interoperable systems continues to be an area for health care improvement as we traverse the quality chasm.
"Pharmacy practitioners can improve their effectiveness in patient education and health behaviors by involving and engaging patients, such as in the evaluation of their individual progress in their care management plan."1

Although emphasis on patient engagement has increased in recent years, it is not a new concept. In fact, the framework itself was created not just with the input from health care stakeholders (e.g., pharmacists, providers, life sciences, managed care, and community), but also patients. Additionally, patient-centeredness is an evaluation component within the framework, further highlighting patient experience as an important quality improvement outcome. To this day, we still grapple with how to define a strong patient experience and what that looks like in various settings, including pharmacies. It is also uncertain how best to capture and use these data to measure improvement: Was the chief complaint resolved? Did the patient understand their care? Would the patient recommend the health care organization? As one of the most trusted and highly visited health care providers, pharmacists are well suited to capture the patient voice and improve patient experience. Advancements in defining meaningful patient engagement in health care, routinely capturing patientreported outcomes, and incorporating patient feedback as part of continuous improvement would surely support traversing the quality chasm.

"The framework tool can help better define the opportunities for quality improvement, narrow the focus for the interventions, and help in the measurement of the progress to goal.".

Since framework development, CQI has continued to gain traction in pharmacy practice, and in some cases, it is mandated by state and local governments. ${ }^{11}$ Additionally, the increase in practice sites seeking accreditation illustrates how much the health care industry is focused on quality improvement. For example, the Center for Pharmacy Practice Accreditation accredits community and specialty pharmacy, as well as telepharmacy and MTM practices, and although the accreditation process includes standards specific to each practice type, CQI program implementation remains a domain for every one of them. ${ }^{12}$

CQI frameworks, such as the one published by JMCP in 2004, continue to be useful tools to guide and monitor improvement as we traverse the quality chasm. Other important levers that must be considered in our current environment include overcoming data challenges at the pharmacy level, so reliable and valid metrics can be developed as a tool to benchmark and measure care improvements. Additionally, in order to meaningfully capture the effect of innovative pharmacy practice, we need to continue our focus on standardization and reporting of pharmacy services. It is still challenging to 
characterize the full effect of pharmacy practice interventions, since reporting elements were not initially standardized. ${ }^{13}$

As we reflect on the history and evolution of pharmacy practice, perceptions of pharmacy, and the health care policy landscape, we find that although we have made significant strides forward as a profession, we still face similar challenges as pharmacists faced over 20 years ago. We still have a great opportunity for innovation and continuous quality improvement; tools such as the framework published by JMCP in 2004 will continue to serve as guides as we trek across the quality chasm.

\section{Authors}

MEL L. NELSON, PharmD, CPHQ, Director, Research \& Operations; CARTER CHAPMAN, PharmD, CPHQ, Executive Fellow; and PATRICK J. CAMPBELL, PharmD, PhD, Senior Director, Research, Pharmacy Quality Alliance, Alexandria, Virginia.

AUTHOR CORRESPONDENCE: Mel L. Nelson, PharmD, CPHQ, Director, Research E Operations, Pharmacy Quality Alliance, 5911 Kingstowne Village Pkwy., Ste. 130, Alexandria, VA 22204. E-mail: MNelson@PQAalliance.org.

\section{DISCLOSURES}

No funding supported the writing of this reflection. The authors have nothing to disclose.

\section{ACKNOWLEDGMENTS}

The authors acknowledge Laura Cranston, the CEO of the Pharmacy Quality Alliance (PQA), for her insights and contributions to this reflection. As the lead of PQA since its inception, her perspective was instrumental in adding first-hand experiences to this commentary.

\section{REFERENCES}

1. Curtiss FR, Fry RN, Avey SG. Framework for pharmacy services quality improvement-a bridge to cross the quality chasm. Part I. The opportunity and the tool. J Manag Care Pharm. 2004;10(1):60-78. Available at: https://doi. org/10.18553/jmcp.2004.10.1.60.

2. Carter BL. Evolution of clinical pharmacy in the US and future directions in patient care. Drugs Aging. 2016;33(3):169-77.

3. Ukens C. Will pharmacists win provider status? Drug Topics. 2001;10:33

4. O'Brien JM. How nurse practitioners obtained provider status: lessons for pharmacists. Am J Health Syst Pharm. 2003;60(22):2301-07.

5. Kohn LT, Corrigan J, Donaldson MS. To Err Is Human: Building A Safer Health System. An Institute of Medicine report. Washington, DC: National Academy Press; 2000.

6. Institute of Medicine. Crossing the Quality Chasm: A New Health System for the 21st Century. Washington, DC: National Academy Press; 2001.

7. Pharmacy Quality Alliance. About PQA. Available at: https://www. pqaalliance.org/our-story. Accessed May 26, 2020.

8. Donabedian A. Evaluating the quality of medical care. Millbank Mem Fun Q. 1966;44(Suppl):166-206.

9. Bingham J, Campbell P, Schussel K, et al. The discharge companion program: an interprofessional collaboration in transitional care model delivery. Pharmacy (Basel). 2019;7(2):68

10. Campbell P, Bingham J, Schussel K, Leal S. U36 Evaluation of the discharge companion program: an interprofessional transitions of care program [abstract]. J Manag Care Spec Pharm. 2018;24(Suppl. 4-a):S102.

11. Quality assurance in the pharmacy. Drug Topics. August 15, 2010. Available at: https://www.drugtopics.com/hse-business-management/ quality-assurance-pharmacy. Accessed May 26, 2020.

12. Center for Pharmacy Practice Accreditation. Website. Available at: https://www. pharmacypracticeaccredit.org. Accessed May 26, 2020.

13. Clay PG, Burns AL, Isetts BJ, et al. PaCIR: a tool to enhance pharmacist patient care intervention reporting. J Am Pharm Assoc (2003). 2019;59(5):615-23. 